Western University Scholarship@Western

Centre for the Study of International Economic Centre for the Study of International Economic

Relations Working Papers

Relations

1984

\title{
Strategic Investments and the Development of Multinationals
}

Ignatius Horstmann

James R. Markusen

Follow this and additional works at: https://ir.lib.uwo.ca/economicscsier_wp

Part of the Economics Commons

Citation of this paper:

Horstmann, Ignatius, James R. Markusen. "Strategic Investments and the Development of Multinationals." Centre for the Study of International Economic Relations Working Papers, 8407C. London, ON: Department of Economics, University of Western Ontario (1984). 
CENTRE FOR THE STUDY OF INTERNATIONAL ECONOMIC RELATIONS

\author{
WORKING PAPER $8407 \mathrm{C}$
}

STRATEGIC INVESTMENTS AND THE DEVELOPMENT OF

MULTINATIONALS

\author{
Ignatius Horstmann \\ and \\ James R. Markusen
}

This paper contains preliminary findings from research still in progress and should not be quoted without prior approval of the authors.

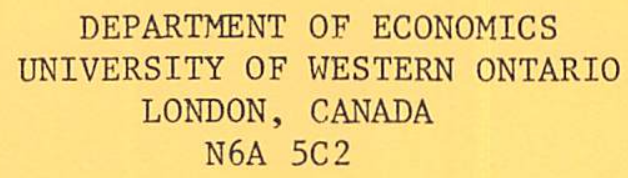

DEPARTMENT OF ECONOMICS N6A 5 C 2

Department of Economics Library
APR 31984
University of Western Ontario




\section{STRATEGIC INVESTMENTS AND THE DEVEIOPMENT OF MULTINATIONALS \\ Ignatius Horstmann \\ and \\ James R. Markusen \\ Department of Economics \\ University of Western Ontario \\ Lond on \\ Canada}

\section{Abstract}

A model to explain the origins of multinationals is developed around the existence of tariff/transportation costs and firm-specific as well as plant-specific sunk costs. A firm wishing to serve a foreign market must either build a branch plant and absorb the latter cost or export and absorb the tariff/transportation cost. In a growing world, a first entrant will preempt entry of home firms in smaller countries by establishing branch plants (i.e., by becoming a multinationa1) if firm-specific and tariff/transportation costs are large relative to plant-specific costs. The relative importance of these costs seems consistent with empirical observation.

January, 1984

The authors would like to thank participants in seminars at M.I.T., Toronto, Boston College, and the N.B.E.R. Summer Institute for helpful comments and suggestions.



Aitir 3 1984

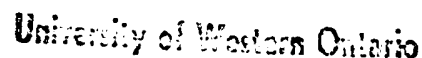




\section{Introduction}

Recently, the activities of multinational enterprises (MNE) have been the focus of a considerable amount of policy debate. This interest has spawned a large number of empirical studies analyzing a wide variety of data on MNE activities. These studies suggest the existence of a number of empirical regularities between the extent of MNE activity in an industry and such variables as the size of scale economies, advertising and product differentiation, the importance of research and development, and the general level of non-production activities. ${ }^{1}$

To date, however, little theoretical work has been done which would help us put these empirical results in perspective, particularly in terms of their relevance to policy issues. What has been done has tended to take the existence of MNE as exogenous and focus on the way in which technological advantage enjoyed by the MNE may affect the gains from trade [Markusen (1984)] and the pattern of production and trade [Helpman $(1983 a, b ; 1984) e^{2}$

While these studies constitute valuable contributions to the debate concerning MNE activities, they fail to address a key issue; namely, the conditions which led to the existence of MNE initially. As such, they offer no predictions about the degree to which MNE activity should be observed across industries nor the effects of various policy changes on the extent of MNE activity.

The model presented in the paper attempts to address these problems. It considers the particular case of a horizontal MNE; that is, a MNE which operates plants producing identical products in several countries. Like the papers of Markusen and Helpman mentioned above, it supposes that production involves certain firm-specific, as opposed to plant-specific activities (things like research and 
development, marketing, organizational activities, etc.). ${ }^{3}$ In a static sense, these firm-specific activities give rise to multi-plant economies of scale that give a MNE an advantage over single-plant firms. In a dynamic sense, sunk costs in firm-specific activities give a firm a strategic advantage over new entrants.

Yet the existence of this advantage does not guarantee that a first entrant will build branch plants (i.e., become a MNE) in preference to exporting. In our model, construction of a branch plant requires that the firm incur a plant-specific cost while exporting requires that the firm bear a per-unit tariff/transportation charge. It is the relationship among the three types of costs (firm-specific, plant-specific, and tariff/transportation costs) in combination with strategic behavior that determine the decision to become a MNE.

The specific details of the model are presented in the next section within the framework of a two-good, two-country general equilibrium model. The model assumes that, initially, one country (the home country) is large relative to the other (the host country) in the sense that all production of one good $(X)$ is carried out in the home country. All host country demand for X is assumed to be met by home country exports. This asymmetry is the result of an assumed smaller initial endowment in the host country and the fact that $X$ production involves scale economies in the form of the above-mentioned firm-specific and plant-specific costs. Over time, it is assumed that the factor endowment of the host country grows in some we11-specified way. The model thus roughly parallels the situation faced by many U.S. firms serving Canadian, European, and Third-World countries in the first half of the twentieth century. 
Section three analyzes the behavior of an existing home country firm in light of the host country demand growth. Here it is shown that if the host country grows large enough (where this is a well-defined notion), then MNE activity is not ensured. In particular, propositions in this section show that MNE activity (branch-plant operation) will occur if firmspecific costs (multi-plant scale economies) and tariff/transportation costs are sufficiently large relative to plant-specific costs. Opposite assumptions on relative costs imply that the home firm does not enter and will simply contimue to export as domestic firms enter in the host country.

These results form the empirically testable proposition that industries which have high firm-specific and tariff/transportation costs relative to plant-specific costs are likely to be those industries in which we observe a high level of MNE activity. This proposition seems perfectly consistent with the results of Caves (1980, 1982).

The final analytical section of the paper discusses the welfare properties of the model. In addition to the usual determinants of welfare (scale economies versus market power), the date of foreign entry emerges as an important welfare variable. Proofs of many of the formal results of the paper are contained in a mathematical appendix.

\section{A General Equilibrium Specification}

This section introduces notation and provides a simple general equilibrium specification of the model. This specification is important for the welfare analysis of Section 4 as well as for establishing the plausibility and consistency of the assumptions used in the analysis of Section 3.

Two goods ( $\mathrm{X}$ and $\mathrm{Y}$ ) are produced from a single factor, labor (L), which is in inelastic supply at any point in time $\left(\bar{L}=L_{x}+L_{y}\right)$ and internationally 
immobile. $Y$ is produced with constant returns by a competitive industry and units are chosen such that $Y=I_{y}, Y$ is used as the numeraire so that the wage rate in terms of $Y$ is equal to one.

To begin producing $x$, a firm must incur the once-and-for-all sunk costs of F (firm-specific cost) and $G$ (plant-specific cost) in terms of $Y$ (or $L$ ). Additional plants may be opened for the cost of $G$ only. The marginal cost (in terms of $Y$ ) of producing $X$ is constant for each plant and identically equal to c. Both home and host country producers of $\mathrm{X}$ have access to the same technology. Producers of $X$ are assumed to maximize the present value of their profits $\left(V_{t}\right)$ in terms of $Y$ and may borrow at a constant rate, $r$, to cover sunk costs. Borrowing in this framework involves the firm borrowing $Y$ to pay for current labor services.

Several simplifying assumptions are made about consumer (1abor) demand. First, the rate of interest, $r$, is fixed by the rate of time preference. Second, current demand for $X$ by a single consumer is assumed to depend only on the current relative price of $X$ in terms of $Y$, denoted $p_{0}$ Total demand by labor, therefore, depends only on $p$ and the number of workers in the economy. Instantaneous revenues net of variable costs in the $X$ industry can then be given by the simple relationship $R_{t}=R_{t}\left(x_{t}\right)$, where $R_{t}()$ is assumed to be continuous and differentiable in $\mathrm{X}$.

An example of consumer preferences which would generate these demand conditions is the case in which consumers possess a separable instantaneous utility function $U=U(X)+Y$ where $U(X)$ is strictly concave; and in which they maximize $U$ discounted at rate, $\rho$, subject to an intertemporal budget constraint which allows borrowing and lending at rate $r$. A single consumer's optimization problem (the time horizon is qualitatively unimportant) is then given by 


$$
\max \int_{0}^{\infty} e^{-\rho t}\left[U\left(X_{t}\right)+Y_{t}\right] d t \text { s.t. } \int_{0}^{\infty} e^{-r t}\left(L_{t}-p_{t} X_{t}-Y_{t}\right) d t=0 .
$$

An interior solution $\left(Y_{t}>0\right.$ for all $\left.t\right)$ requires that $r=\rho$. If, for instance, $\rho<r$ all consumers would wish to lend and consume no $Y$, a situation which we assume always exceeds the borrowing requirements of the firm. With the marginal utility of $Y$, then, equal to one and $r=\rho$, we have that $U^{\prime}(X)=p$ as the instantaneous first-order condition for $\mathrm{X}$. Inverting $U^{\prime}(\cdot)$, we will have instantaneous demand functions that depend only on current price. Producers of $X$ thus face the simple total demand function $X=U^{\prime-1}(p) \bar{L}$ and the constant rate of interest $r=\rho$. The revenue function $R_{t}\left(X_{t}\right)$ follows directly. At $t=0$, it is assumed that firms already exist in the host country who are producing $X$ and who, therefore, have incurred the firm-specific cost $F$ and at least one plant-specific cost G. Host country demand is assumed to be too small initially to support any domestic $X$ producers. In order to focus on the entry problem in the host country (i.e., on the origins of MNE activity) we make two simplifying assumptions. First, there is only one home country firm which can provide $X$ (either through exports or domestic production) to the host country..$^{4}$ Second, we assume "segmented markets" such that $\mathrm{X}$ can be exported from the home country to the host country, but no $\mathrm{X}$ can be profitably exported back to the home country. This could be due either to a prohibitive tariff imposed by the home country or simply to the fact that the industry equilibrium in the home country is such that exporting by host country firms is simply not profitable (i.e., the home country has achieved a steady-state equilibrium). In either case, the effect of this (combined with the technology assumptions) is to permit both home and host country firms to make their entry decisions based solely on host country demand. 
Finally, it is assumed that the host-country labor force and therefore demand for $X$, grows exogenously with time. Specification of the exact manner of this demand growth is delayed until the next section.

It is perhaps easier to understand the structure of this model if one considers it first in the context of a simple static representation. Such a representation can also serve as a useful intuitive aid to the analysis of the next section. Figure 1 shows the static production frontier for a country as $\bar{Y} G F \bar{X}$ where $\bar{Y} G$ and $G F$ are plant-specific and firm-specific cost, respectively. The slope of $\overline{F X}$ is equal to the constant marginal cost, $c$. The average cost of producing $X$ in terms of $Y$ is given by the simple formula

$$
A C_{x}=I_{x} / X=\left(\bar{I}-I_{y}\right) / X=(\bar{Y}-Y) / X
$$

Consider point $A^{\prime}$ in Figure 1. The average cost of producing this amount of $\mathrm{X}$ is, from (2), simply the slope of the line passing through $\overline{\mathrm{Y}}$ and $\mathrm{A}^{\prime}$. Average cost is, of course, everywhere decreasing in $\mathrm{X}$.

Total labor income in terms of $Y$ is simply $L_{x}+L_{y}=\bar{L}=\bar{Y}$ in Figure 1 . We can then construct labor's general equilibrium demand curve by an offer curve approach: swing a price line through $\bar{Y}$ in Figure 1 and observe the optimal consumption choice at each price ratio. This gives us the offer curve OC in Figure 1 which will have this general shape provided that the elasticity of substitution is greater than one.

Figure 1 shows a particular outcome in which oc lies everywhere above FX. This "small country case" occurs when $F$ and $G$ are large relative to $\bar{L}$. At any price such as $\mathrm{p}$, the quantity demanded (point $A$ ) is less than the quantity necessary to reduce average cost to $p$ (point $A^{\prime}$ ). No $X$ would be produced in autarky. If we now allow the economy to grow (increase $\bar{L}$ ), the offer curve and the production frontier must eventually converge and intersect since demand is growing while average cost is constant. 
Figure 1

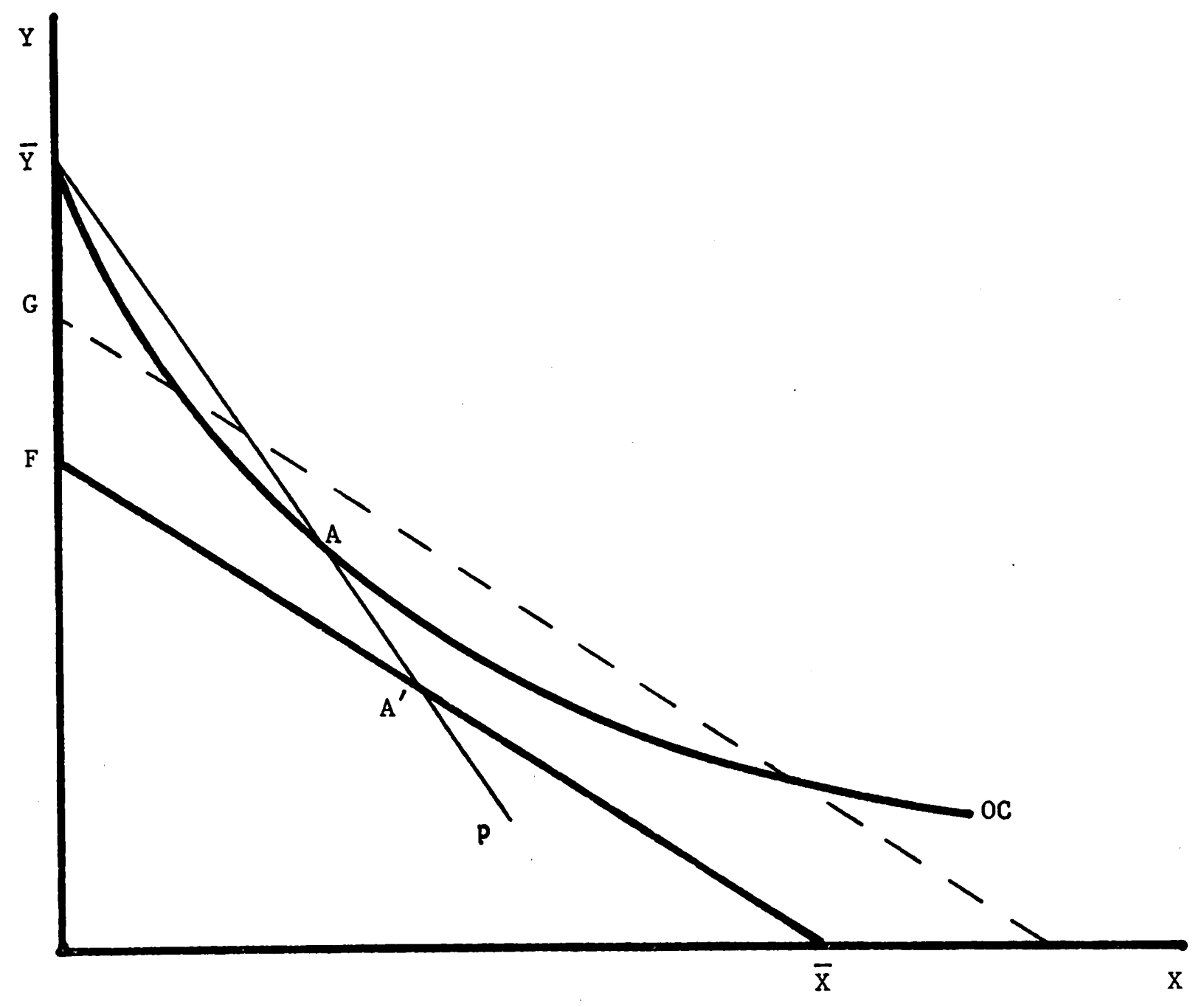


The dashed line in Figure 1 gives the production frontier that would confront a foreign MNE which wanted to open a branch plant in this country; that is, the MNE need not incur the firm-specific cost F. As drawn in Figure 1, the MNE production frontier is cut by the offer curve, OC, indicating that a branch plant would be profitable whereas entry by a new domestic firm would not. The dynamic equivalent of this for our model is that the MNE is always capable of preempting a new entrant by building a branch plant. Whether or not it would wish to do so in preference to exporting is the subject of the next section.

\section{The Dynamics of Multinational Behavior ${ }^{5}$}

Given the assumptions of the previous section, it would be trivial to provide conditions under which the MNE would operate a host country plant if it were never threatened with entry by host country producers. This would side-step, however, the major issue relating to MNE activity. In particular, the key characteristic of situations involving MNE activity is that production in the host country is carried out by a branch plant of the MNE rather than by potential independent domestic firms. The issue which must be addressed, then, is whether, in the face of potential entry by domestic producers, profit maximizing behavior implies production by an MNE plant rather than by an independent domestic producer (or perhaps that all demand for $\mathrm{X}$ is simply met by MNE exports).

To deal with this issue, we assume that, in addition to the MNE, there exist $n>2$ potential host country producers having access to the same technology as the MNE. ${ }^{6}$ That is, any new domestic firm must incur the once-for-all firm specific cost, $F$, as well as the per-plant cost of G. They also produce with the same marginal cost, $c$, as the MNE. Of course, the MNE must incur the plant-specific cost, G (but not F), if it opens a host-country branch plant. 
Host-country demand for $\mathrm{x}$, from before, is defined implicitly by $D(X, P, t)$ with $\frac{\partial x_{t}}{\partial p_{t}}<0, \frac{\partial X}{\partial t} \geq 0$ for all $t$ and $\lim _{t \rightarrow \infty} \frac{\partial x}{\partial t}=0$. Further restrictions on demand will be delayed until later in this section.

The problem which each firm (i.e. the MNE and each potential entrant) faces is to choose an investment and output strategy which maximizes the present value of the stream of profits, $V_{t}$, accruing to that firm. Investment in this situation is defined simply as the opening of a host-country plant; and the cost of investment is the appropriate setup costs (G or $F+G$ ). Since we focus on closed-loop solution to this problem, the strategies of each firm will be functions of the state of the world at time $t$. We define the history vectors, $\mathrm{H}_{t}^{-}$and $\mathrm{H}_{t}^{+}$at time $t$ as the number of plants operated by each firm prior to the investment decision at time $t\left(\mathrm{H}_{t}^{-}\right)$and after the investment at time $t\left(\mathrm{H}_{t}^{+}\right)$, respectively. The investment strategy of firm $j$ will then be a rule $I^{j}: H_{t}^{-} \rightarrow\{0,1\}$ mapping from histories to investment decisions. The outcome of the investment rule at time $t$ will be summarized by $I_{t}^{j}$, with $I_{t}^{j}=0$ indicating no investment at time $t$ and $I_{t}^{j}=1$ indicating investment at $t$. The output strategy of firm $j$ will be a rule $\mathrm{x}^{j}: \mathrm{H}_{t}^{+} \rightarrow[0, \overline{\mathrm{x}}]$ mapping from postinvestment history to an output space, where $\bar{x}$ is the upper bound on this space. 7

The equilibrium of the game is a perfect Nash equilibrium in output and investment rules. Thus, in particular, each firm's investment rule must maximize the present value of its profits at each $t$ given its output rule and the investment and output rules of all other firms. Further, this must be true for arbitrary (in the sense of off the equilibrium path) histories. The same must be true of the firm's output rule. The allocation which results from 
the play of each firm's equilibrium strategy at any $t$ will be represented by the pair $\left(x_{t}^{j}, I_{t}^{j}\right)$.

Given this framework, the precise nature of the equilibrium allocation for this game will depend upon the number of potential host country producers supportable in equilibrium. In what follows, we consider two cases : one in which host country demand is such that one host country producer can be supported in equilibrium but not two; and a second in which two, but not three host country producers can be supported. The ways in which the results of our model could be extended to more general situations will become apparent from the analysis of these two cases.

\section{A. Multinationals and Potential Entry: One Domestic Plant}

As a first specification of the problem, we consider a situation in which, initially, host country demand is sufficiently small relative to the setup costs that all demand for $\mathrm{X}$ is met by MNE exports. We then allow demand to grow large enough to support a single host country producer plus exports, and consider the incentives for this production to be carried out by the MNE rather than an independent domestic producer. Formally, we impose the following additional restrictions on the host country demand function.

(i) $D(x, p, 0): \int_{0}^{\infty} R_{t}\left(x^{a}\right) e^{-r t} d t-F-G<0$

where $x^{2}$ is the output an independent domestic firm would produce if it were a monopolist for all $t$ (the autarky output)

(ii) $D(X, p, 0): R_{0}\left(X_{h}^{m}\right)-r G<R_{0}\left(X_{E}^{m}\right)-s X_{E}^{m}$ while $R_{0}\left(X_{E}^{m}\right)-s X_{E}^{m}>0$ where $X_{E}^{m}$ is the profit maximizing amounts of exports by the MNE to the host country, while $x_{h}^{m}$ is the monopoly output of $x$ were the MNE to operate a host country branch plant. s represents the per-unit tariff/transportation cost. 8 
(iii) $D(X, P, t): \int_{t}^{\infty} R_{T}\left(X_{D}^{c}\right) e^{-r(T-t)} d \tau-F-G Z(s) 0$ as $t z(s) t_{1}$ where $X_{D}^{c}$ is the equilibrium output of an independent domestic firm competing against MNE exports.

$$
\text { (iv) } D(X, p, t): \int_{t}^{\infty} R_{T}\left(x_{h}^{c}\right) e^{-r(T-t)} d \tau-G<0 \quad \forall t
$$

where $x_{h}^{c}$ is the equilibrium output of a firm with a single host country plant competing against another firm with a single host country plant, given MNE exports are zero.

The first two of these assumptions imply that, initially, there are no independent host country producers, and that the profit maximizing strategy for the MNE is to meet all host country demand through exports. The last two assumptions imply that there is some $t=t_{1}$ such that an independent host country producer could enter and compete against MNE exports, but that two domestic plants could not produce and earn positive profits.

Given these demand restrictions, we want to characterize the equilibrium of the game described above. Because the formal statement and proof of the equilibrium is rather long and involved, we have left it to the Appendix. We present below the allocations which result from the play of each firm's equilibrium strategy, as well as some informal discussion of the reasons that these allocations are equilibrium allocations.

With demand capable of supporting only one host country firm, the equilibrium of the game is unique with the MNE always building a host country branch plant, thereby preempting entry by any independent host country firms. Nonetheless, the time at which the MNE invests can vary. In particular, we can identify two distinct times at which the MNE might build its single host country plant. The first is given below as: 
Proposition 1. If there exists a $\hat{t}<t_{1}$ such that

$$
R_{\hat{t}}\left(X_{h}^{m}\right)-r G=R_{\hat{t}}\left(X_{E}^{m}\right)-s X_{E}^{m}
$$

then the equilibrium involves the MNE playing $\left(\mathrm{X}_{\mathrm{E}}^{\mathrm{m}}, 0\right) 0 \leq t<\epsilon$

$\quad\left(x_{h}^{m}, 1\right) t=\hat{t}$
and a11 entrants playing $(0,0)$ for all $t . \quad\left(x_{h}^{m}, 0\right) t>\hat{t}$

The reader should recognize (3) as defining the optimal time for an exporting firm to build a host country branch plant in the monopoly (i.e. no entry) situation. If the MNE invests at $\hat{t}<t_{1}$, then, in fact, no entry will occur and the investment strategy will be optima1. 9 Proposition 1, therefore, defines the case of what Bain called "blockaded entry", in that, were the MNE to act as a myopic (in the sense of ignoring potential entry) profit maximizer, it would preempt entry by independent host country firms. From (3), it is clear that this result is more likely to occur when $s$ is large relative to $G$.

If $s$ is sufficiently small relative to $G$ there may be no $t \leq t_{1}$ for which (3) holds. Nonetheless, it will still be in the MNE's interest to build a host country branch plant and preempt entry by independent host country firms. In this case, however, entry preemption will be a strategic action by the MNE. These results are given below.

Proposition 2. If, for all $t \leq t_{1}$

$$
R_{t}\left(X_{h}^{m}\right)-r G<R_{t}\left(X_{E}^{m}\right)-s X_{E}^{m}
$$

then the equilibrium allocation will be:

$$
\begin{aligned}
& \text { (i) For the MNE } \\
& \left(x_{E}^{m}, 0\right) \quad 0 \leq t<t_{1} \\
& \left(x_{h}^{m}, 1\right) \quad t=t_{1} \\
& \left(x_{h}^{m}, 0\right) \quad t>t_{1}
\end{aligned}
$$




\section{(ii) For all domestic producers $\quad(0,0) \quad$ tt}

The logic behind this result is quite straightforward. If the MNE does not preempt entry by investing on or. before $t_{1}$, an independent host country firm will enter. The MNE's profits will then be the present value of the export revenues it earns in a Cournot duopoly. Should the MNE preempt entry, it maintains a monopoly position. It can then coordinate host country production and exports (setting exports equal to zero in this case) to earn more than the sum of its own profits and the profits that the independent host country firm would earn were the MNE not to preempt entry. Therefore, it will always pay the MNE to build a branch plant and preempt entry. By so doing, it captures all of the rents (as opposed to only a share of the rents) available in the market.

Several points should be noted about the results. in Proposition 2. First, since the equilibrium is perfect, the entry preemption by the MNE involves no incredible threats. Second, while the MNE invests at $t_{1}$ as Lemma 1 in the Appendix shows, there exists an open interval $\left(t_{1}-\varepsilon, t_{1}\right)$ such that MNE profits are larger if it invests at any $t$ on this interval rather than not investing at all. Thus, the entry preemption result does not rely on the MNE having to invest at $t_{1}$ and no sooner. 10

The results of Propositions 1 and 2 provide a formalization of an early explanation for the existence of MNE activity. This explanation focused on the existence of "tariff walls" as a cause of multinationals. It argued that an MNE branch plant was the result of an exporting firm "jumping" host country "tariff wal1s". Given F,G > 0, then the results of Proposition 1 (or Proposition 2) go through as long as $s>0$. If one interprets $s$ as a tariff, then these two propositions capture the sense in which "tariff walls" may be an explanation for MNE activity. 11 


\section{B. Multinationals and Potential Entry: Two Domestic Plants}

This section generalizes the analysis of the preceding section to a situation in which host country demand grows large enough to support two producers in the host country. This small increase in generality will permit us to derive additional predictions concerning the relationship between the existence of MNE's and various parameters while still keeping the model reasonably tractable. In addition it will serve to indicate the way in which this model would generalize to larger numbers of entrants and MNE's.

To incorporate this generalization into the preceding mode1, we need only modify demand assumption (iv) from the preceding section. In its place, we assume the following:

$$
\begin{aligned}
& \text { (iva) } D(X, p, t): \int_{t}^{\infty} R_{\tau}\left(x_{h}^{c}\right) e^{-r(\tau-t)} d \tau-F-G Z(s) 0 \forall t z(s) t_{2} \\
& \text { where } X_{h}^{c} \text { is defined as in (iv) above. } \\
& \text { (ivb) } D(x, p, t): \int_{t_{3}}^{\infty} R_{T}\left(x_{2 D}^{c}\right) e^{-r(\tau-t)} d \tau-F-G z(s) 0 \quad \forall t z(s) t_{3} \\
& \text { where } x_{2 D}^{c} \text { is the equilibrium output of a firm with a single } \\
& \text { host country plant competing against another firm with a } \\
& \text { single host country plant and } \mathbb{M N E} \text { exports. } t_{3} \text { is assumed } \\
& \text { strictly larger than } t_{2} \text {. } \\
& \text { (ivc) } D(x, p, t): \int_{t}^{\infty} R_{T}\left(x_{2 h}^{c}\right) e^{-r(T-t)} d T-G<0 \quad \forall t \\
& \text { where } x_{2 h}^{c} \text { is the equilibrium output of a firm with a single } \\
& \text { host country plant competing against two other firms each with } \\
& \text { a single host country plant, given MNE exports are zero. }
\end{aligned}
$$

This change makes it possible for demand to support two separate host country plants plus exports, but not three host country plants. 
As with the preceding section, we do not provide a complete statement and proof of the equilibrium here. We do characterize a number of the properties of different equilibrium paths and the allocations which result. The proofs are again provided in the Appendix.

It should be clear from the analysis of the preceding section that if the MNE invests at some $\hat{t} \leq t_{1}$, it can preempt entry by a domestic producer until at least $t_{2}$. Unlike the previous case, however, the MNE cannot preempt all entry in equilibrium. This result is captured in the following proposition. Proposition 3. In equilibrium, the investment rule for the MNE must be such that if there exists a $t=\hat{t}$ for which $I_{\hat{t}}=1$, then $I_{t}=0$ for all $t \neq \hat{t}$.

The intuition behind this result is very simple. Given the assumed cost structure, the profit maximizing output for the MNE with two branch plants is identical to the profit maximizing output if it operates only one branch plant. 12 Therefore, in a perfect equilibrium, the investment and output decisions of the entrants would be the same whether the MNE operated a single branch plant or two plants. Since the second plant would cause the MNE to incur the cost G, it would not be optimal (i.e. it would not be an equilibrium strategy) for the MNE to invest more than once. Therefore, in particular, it is not possible for the MNE to proliferate branch plants and so preempt entry by all independent host country producers. 13

Given this, the question then becomes whether or not the MNE still has an incentive to operate a branch plant in the host country. The answer to this question turns out to involve a notion of appropriability not dissimilar to that discussed by Magee (1977). By incurring the cost, G (i.e. by operating a branch plant) the MNE obtains returns both in the form of lowered costs for production of $X$ as well as from reduced competition from other firms. In the 
preceding case, the MNE could preempt all entry and therefore was able to appropriate all of these latter gains for itself. In the case considered here, Proposition 3 shows that total entry preemption is not possible. Therefore, by operating a branch plant, the MNE creates a situation akin to an externality problem in the sense that while its investment reduces competition (the equilibrium becomes a duopoly instead of a triopoly) the MNE does not capture all of the benefits from this (the reduced competition does not represent a private benefit).

Because of this appropriability problem, it will not always be in the MNE's interest to open a host country branch plant. We can provide, however, conditions which are sufficient to guarantee that the MNE either will or will not operate a plant in the host country. Propositions 4 and 5 below provide conditions which guarantee that the MNE will operate a host country branch plant (Proposition 4) and that this plant will be built prior to entry by any independent host country firm (Proposition 5).

Proposition 4. If an investment strategy for the $\mathrm{MNE}$ implies that $I_{t}=0$ for a11 $t \leq t_{1}$; and if there exists a $\bar{t}$ such that $t_{1}<\bar{t}<t_{3}$ and

$$
R_{\bar{t}}\left(X_{h}^{c}\right)-r G=R_{\bar{t}}\left(X_{E}^{c}\right)-s X_{E}^{c}
$$

then $I_{-}=1$ for the $M N E$.

Proposition 4 simply implies that if a $t=\bar{t}$ exists, then any potential equilibrium investment strategy for the MNE must imply that the MNE will invest

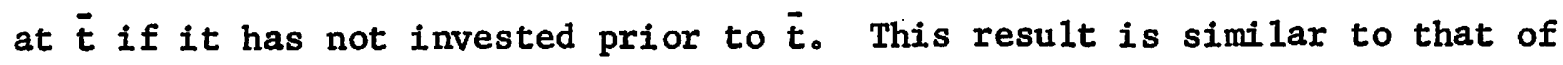
Proposition 1. In particular it implies that if $s$ is large relative to $G$ (in the sense that (4) holds), then it will be profitable for the MNE to invest at $\bar{t}$ (assuming it has not invested previously), even if all future potential entry 
is ignored. It is, therefore, a "blockaded entry" results of sorts, with the second entrant being the firm that is preempted.

While Proposition 4 provides conditions sufficient to guarantee that the MNE operates a branch plant, it does not guarantee that the MNE opens the branch plant prior to any entry by an independent host country firm. The following proposition provides an additional restriction which guarantees this outcome.

Proposition 5. If there exists a $t=\bar{t}$ defined as in Proposition 4; and if, in addition, $t_{1}<\bar{t}<t_{2}$, then the equilibrium strategy for the MNE implies that $I_{\hat{t}}=1$ for some $\hat{t} \leq t_{1}$.

The implication of these two propositions for the likelihood of MNE production can be seen if one considers the relationship between $\bar{t}$ and $t_{1}$ and $t_{2}$. From (4), it is clear that $\bar{t}$ is independent of the firm specific cost, $F$. $t_{1}$ and $t_{2}$ are functions of both $F$ and the plant specific cost $G$. One can imagine, therefore an experiment in which $F$ were increased and $G$ decreased such that $t_{1}$ and $t_{2}$ were unchanged (this would involve having $d F=-d G$ ). This would have the effect of reducing $\bar{t}$ and increasing the likelihood that $t_{1}<\bar{t}<t_{2}$; or it would have the effect of increasing the likelihood (in any arbitrarily chosen case) that the MNE is the first firm to operate a host country plant. The limiting case of such an experiment would be a situation in which $G=0$. Then for any non-zero s, the conditions of both Propositions 4 and 5 are fulfilled; and, as is obvious in this case, the MNE will operate a branch plant prior to $t_{1}$ with certainty (in fact, it will operate a branch plant at time zero). 14 Therefore, a prediction of this model would be that MNE activity is more likely the larger are the firm-specific and tariff/transportation costs relative to plant specific costs. That is, under this more general specification, it will 
be the combination of large firm-specific costs and tariff/transportation costs (where large is relative to plant-specific costs) that will give rise to MNE production. This is in contrast to the previous case in which all that was required was positive $s$ and $F$.

In addition to the above result concerning conditions under which the MNE will operate a host country branch plant, we can also provide a result concerning conditions under which it will not operate a branch plant. This result is :

Proposition 6. If, for $F=0, G>0, R_{t}\left(x_{h}^{c}\right)<2 R_{t}\left(x_{2 h}^{c}\right)$ for all $t$, then there exists an $\epsilon>0$ such that, for all $0<s \leq \epsilon$, the equilibrium strategy for the MNE implies that $I_{t}=0$ for all $t$.

Stated very simply, this result says that if the tariff/transportation cost, $s$, is sufficiently small, then the profit which would accrue to the MNE from investing in the host country (which instantaneously, would be at least $R_{t}\left(X_{h}^{c}\right)$ ) are not sufficiently large relative to the profits it would earn from exporting (at least $R_{t}\left(x_{2 h}^{c}\right)$ instantaneously) to justify the investment cost, G. ${ }^{15}$ Given this, the MNE's equilibrium strategy will imply no investment. This proposition then gives us the other side of the predictions from Propositions 4 and 5. In particular, it indicates that MNE activity is less likely the smaller firm-specific and tariff/transportation costs are relative to G. This complete prediction concerning MNE activity seems to be supported by the empirical work of Caves (1983) and others.

C. Mulinationals and the Depreciation of the Intangible Asset

While our model has focused on the multinational exploitation of its tangible assets to preempt entry in a growing economy, it is also possible to give this model an orientation more closely related to that of Magee (1977). In 
particular, one could assume that demand in the host country is stationary but that the MNE's intangible asset depreciates over time. Suppose for instance that the MNE possesses a patent on a particular technology and that the life of the patent is $t_{f}$ years. Then it is easy to show that this situation can be modelled such that it fits into the framework of the previous sections and so similar results obtain.

To see this, suppose we consider the model in which demand (now stationary) is large enough to support one host country plant but not two. Over the period $\left[0, t_{f}\right]$ a domestic producer, were it to operate, mast use a more costly technology than the MNE. The instantaneous increment in costs from using the second-best technology is defined as $\phi$. At $t_{f}$ the domestic firm can acquire the first-best technology of the MNE. If we define $F(t)$ as

(5) $\quad F(t)=\int_{t}^{t} \phi e^{-r(T-t)} d \tau$

then clearly $\frac{d F}{d t}<0$, or the MNE advantage declines over time. This then allows us to define a set of demand conditions analogous to those of Section B. In particular, we could now have

$$
\begin{aligned}
& \text { (i) } D(X, p, t): \int_{t}^{\infty} R_{T}\left(X_{D}^{c}\right) e^{-r(T-t)} d \tau-F(t)-G \leq 0 \quad 0 \leq t \leq t_{1} \leq t_{f} \\
& \text { (ii) same as (ii) in Section } B \\
& \text { (iii) } D(X, p, t): \int_{t}^{\infty} R_{T}\left(X_{D}^{c}\right) e^{-r(\tau-t)} d \tau-F(t)-G \geq 0 \quad t \geq t_{1} \\
& \text { (iv) } D(X, p, t): \int_{t}^{\infty} R_{T}\left(X_{h}^{c}\right) e^{-r(\tau-t)} d \tau-G<0 \forall t
\end{aligned}
$$

Given this, it is clear that the results of section B continue to go through and we again get the MNE preempting entry by exploiting its intangible asset prior to its total depreciation and building a host country branch plant. 
4. Welfare Analysis

Deriving the welfare properties of the equilibria examined in the previous section is not at all a simple matter. The existence of scale economies and imperfect competition implies prices in excess of marginal costs and thus the non-optimality of free-market equilibrium. In fact the non-convexity of the production set implies that marginal-cost pricing is not necessarily optimal either (Markusen and Melvin (1984)). There is also the intertemporal issue about how two alternative income streams should be evaluated. The final question is what are the relevant comparisons? Should the free market welfare level be compared to first-best policy options involving optimal subsidies and lump-sum taxes or to more relevant second-best alternatives?

In this section we shall restrict ourselves to a limited range of issues and consider them only for a rather simple case. We shall in particular consider only the case in which the host country does not grow beyond the point where it can support only a single domestic plant. We shall then compare the free-market solution involving MNE exports followed by branchplant production to a simple "autarky" option in which the country prohibits either imports or branch-plant production by the MNE. This comparison reveals that the date of foreign entry is an important welfare variable and illustrates the trade- off between technical efficiency (the host country saves F) and market power (the MNE repatriates profits).

If we let " $m$ " refer to equilibrium quantities when the Mase is either exporting or producing in a host country branch plant; and let "a" refer to host country autarky outputs, then the static revealed preference criterion for the host country to be better off with the MNE than in autarky is 


$$
c_{y}^{m}+p^{m} c_{x}^{m} \geq c_{y}^{a}+p^{m} c_{x}^{a}
$$

where $C_{i}$ is consumption of good $i$ in the host country. If we assume that the government can transfer income across time as well as across individuals, we can generalize (6) by integrating over time.

$$
\int_{0}^{\infty} e^{-r \tau}\left(c_{y}^{m}+p^{m} c_{x}^{m}\right) d \tau \geq \int_{0}^{\infty} e^{-r \tau}\left(c_{y}^{a}+p^{m} c_{x}^{a}\right) d \tau
$$

This is, alternatively, not an unreasonable criterion if the marginal utility of income is always equal to 1 as it is for the utility function discussed in Section 2.

In autarky, we have the market clearing conditions at each instant

$$
C_{y}^{a}=Y^{a}, \quad C_{x}^{a}=x^{a}
$$

With trade, we must have long-run current account clearing, or the value of consumption equal to the value of production at world prices. We assume that imports incur transportation charges rather than tariffs to avoid tax revenue terms in the welfare expression. Domestic prices in $(\lambda)$ are then the same as the "world prices" at which payments must balance. Since labour is assumed to be immobile (the country could borrow goods to redistribute consumption intertempora11y), this constraint is given by

$$
\int_{0}^{\infty} e^{-r \tau}\left(c_{y}^{m}+p^{m} c_{x}^{m}\right) d \tau=\int_{0}^{\infty} e^{-r \tau}\left(Y^{m}+p^{m} x^{m}-\pi\right) d \tau
$$

where $\pi$ is the profits repatriated by the MNE from its branch plant (if it exists) at each instant. Substituting (8) and (9) into (7), the condition for gains becomes

$$
\int_{0}^{\infty} e^{-r \tau}\left(Y^{m}+p^{m} X^{m}-\pi\right) d \tau \geq \int_{0}^{\infty} e^{-r \tau}\left(Y^{a}+p^{m} X^{a}\right) d \tau .
$$

Now subtract the total labour endowment $\bar{L}=L_{x}^{m}+I_{y}^{m}=L_{x}^{a}+L_{y}^{a}$ from both sides. 


$$
\int_{0}^{\infty} e^{-r \tau}\left[\left(Y^{m}-L_{y}^{m}\right)+\left(p^{m} x^{m}-I \frac{m}{x}-\pi\right] d \tau z \int_{0}^{\infty} e^{-r \tau}\left[\left(Y^{a}-L_{y}^{a}\right)+\left(p^{m} x^{a}-L_{x}^{a}\right)\right] d \tau .\right.
$$

The assumption of competition in $Y$ implies profits in $Y$ are zero at each instant; i.e., $\left(Y^{m}-L_{y}^{m}\right)=\left(Y^{a}-L_{y}^{a}\right)=0$ so (11) reduces to

$$
\int_{0}^{\infty} e^{-r \tau}\left[\left(p^{m} x^{m}-L_{x}^{m}\right)-\pi\right] d \tau \geq \int_{0}^{\infty} e^{-r \tau}\left(p^{m} x^{a}-L_{x}^{a}\right) d \tau
$$

Assume as in Section 3 that the host country government imposes no taxes. In this case the left-hand side of (12) is always zero. Up untiI $\hat{t}$ (the point at which the MNE sets up a branch plant), there is no production of $X$ in the host country so that $X^{m}=L^{m}=\pi=0$. After $\hat{t}$, we assume that the MNE repatriates all profits so that $\left(\mathrm{p}^{\mathrm{m}} \mathrm{x}^{\mathrm{m}}-\mathrm{L}_{\mathrm{x}}^{\mathrm{m}}\right)=\pi$ at each instant. The sufficient condition for gains in (12) thus reduces to

$$
\int_{0}^{\infty} e^{-r \tau}\left(p^{m} x^{a}-L_{x}^{a}\right) d \tau \leq 0
$$

A sufficient condition for the free-market solution to improve on autarky is thus that the present value of profits from producing the autarky outputs at MNE equilibrium prices is negative. Note again that this condition obtains regardless of when or if the MNE switches from exporting to branch-plant production.

This result is illustrated in Figure 2 for the static-equivalent case. The production frontier is $\bar{Y}_{G F X}$ for the autarky case while the MNE can produce along $\bar{Y}_{\mathrm{GX}}$ since it does not have to incur $F$. Suppose that the MNE equilibrium price ratio is $\mathrm{p}^{\mathrm{m}}$. Then the host country's budget line is $\overline{\mathrm{YN}}$ regardless of whether it is importing $X$ or acting as a host to a MNE branch plant. In the former case, the actual production is $\bar{Y}$ while in the latter case domestic labour is paid the average cost of producing $\mathrm{X}$, given by 


\section{Figure 2}

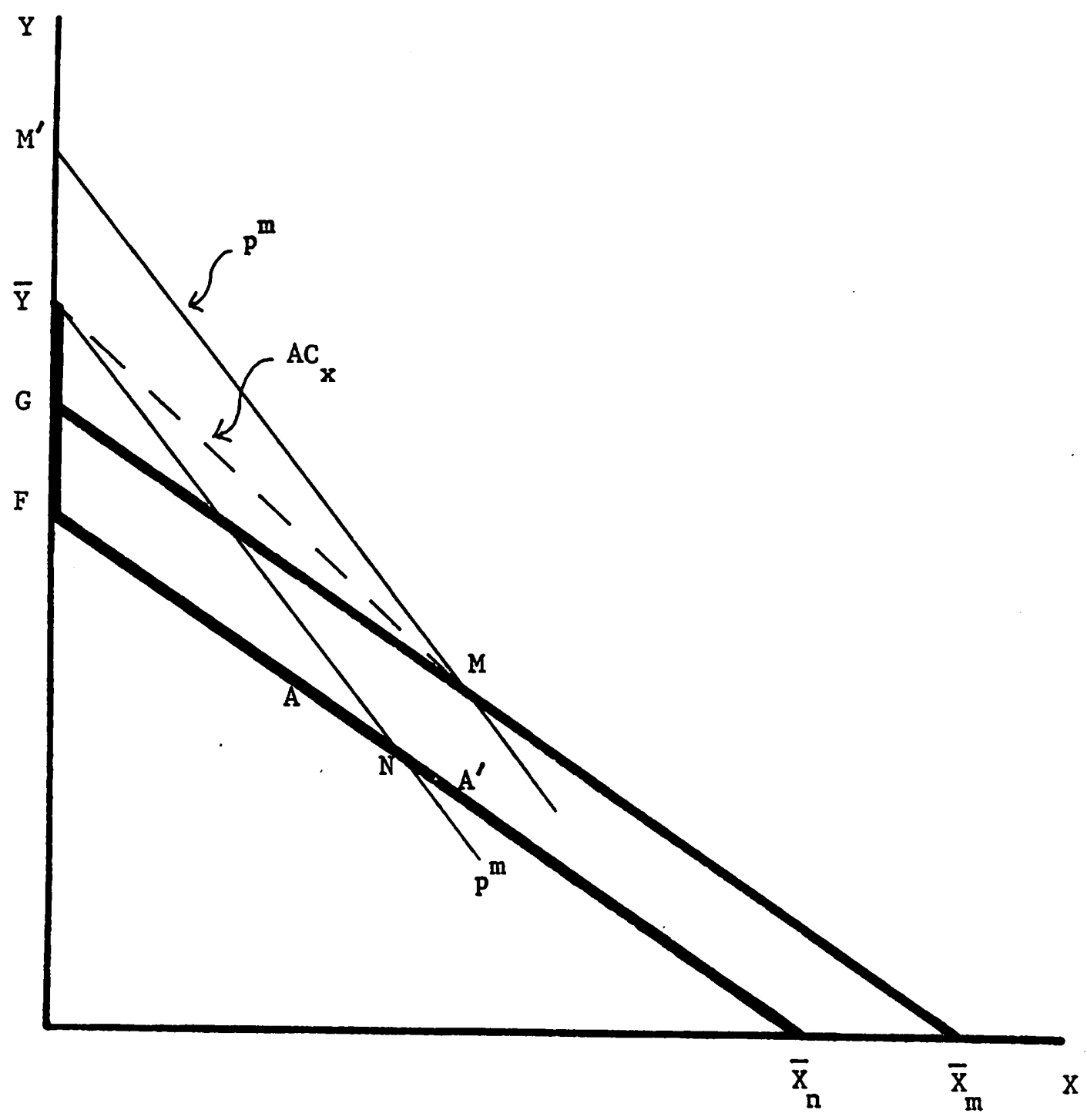


$A C_{X}=(\bar{Y}-Y) / X$ as discussed in Section 2. Tota1 host councry income is then given by $\mathrm{Y}+\left(\mathrm{AC}_{\mathrm{X}}\right) \mathrm{X}=\overline{\mathrm{Y}}$ as well. In the former case income equals GNP while in the latter case income falls short of GNP (point $M^{\prime}$ in Figure 2) by the value of repatriated profits $\left(M^{\prime}-\bar{Y}\right)$.

The geometric equivalent in Figure 2 of the algebraic criterion in (13) is whether or not the autarky equilibrium along $\bar{Y}_{G F X} \bar{X}_{n}$ is to the left (point A) or right (point $A^{\prime}$ ) of $N$. In the former case, the production revenue at $p^{m}$ is less than the cost $(\bar{Y})$ and thus profits from producing $A$ at $\mathrm{p}^{\mathrm{m}}$ are negative. The strict inequality holds in (13) and we see that $\mathrm{N}$ is revealed preferred to $A$ in Figure 2. The opposite comparison applies to $A^{\prime}$, in which case autarky is superior to the MNE equilibrium.

Equation (13) will not necessarily hold given the behavioral assumptions used in Section 3. Consider the time interval $t=[0, \infty]$ and let $t^{*}$ denote the time that a domestic firm would find it profitable to enter in autarky. Note that up to $t^{*}$, we must have $\left(p^{m} x^{a}-L_{x}^{a}\right)=0$ since nothing would be produced domestically by definition of $t^{*}$. Second, note again that due to identical marginal costs and demand, the profit-maximizing prices and outputs of the MNE branch plant and the domestic firm are the same $\left(p^{a}=p^{m}\right.$ for $\left.t>\max [t *, \hat{t}]\right)$. If $\hat{t}<t^{*}$, it must therefore be the case that

$$
\int_{\hat{t}}^{\infty} e^{-r \tau}\left(p^{m} x^{a}-L_{x}^{a}\right) d \tau \leq 0 \text { if } \hat{t}<t^{*} .
$$

Since we have also noted that $\left(p^{m^{2}} x^{a}-I_{x}^{a}\right)=0$ for all $t<t^{*}$, we must then have

$$
\int_{0}^{\infty} e^{-r \tau}\left(p^{m} x^{a}-L_{x}^{a}\right) d \tau \leq 0 \text { if } \hat{E}<t^{*} \text {. }
$$

This is, of course, the sufficient condition in (12) for gains. Thus viewed over the entire time horizon $t=[0, \infty]$, a sufficient condition for the free-market MNE equilibrium to be superior to autarky is simply that the MNE 
finds it profitable to build its branch plant before a home firm would have found it profitable to enter in autarky.

As noted earlier, this outcome does not seem inevitable with the CournotNash behavioral assumption. In fact, if the equilibrium is the one defined by Proposition 2 it will not. occur. In this case, since $R\left(X_{h}^{m}\right)-\left[R\left(X_{E}^{m}\right)-s X_{E}^{m}\right]<r G$, the MNE will seek to delay investment as long as possible while still preempting entry ( $i . e .$, the MNE will invest at $t_{1}$ ). Since the date at which a domestic entrant could successfully compete against exports $\left(t_{1}\right)$ is later than the date it could enter in autarky $\left(t^{*}\right)$, we will have $\hat{t}>t^{*}$. In that case, since the host country price will be higher under the exporting scheme (marginal cost is higher due to the shipping costs while demand is the same) we will have $\mathrm{p}^{\mathrm{m}}>\mathrm{p}^{\mathrm{a}}$ for the interval $\mathrm{T}=\left[t^{*}, \hat{\mathrm{t}}\right]$. The inequality in (13) thus need not follow if $\hat{\mathrm{t}}>\mathrm{t}^{*}$.

In order to put the point more strongly, consider (15) over the interval $[t *, \infty]$. It is easy to show that

$$
\int_{t^{*}}^{\infty} e^{-r \tau}\left(p^{m} x^{a}-L_{x}^{a}\right) d \tau \leq 0 \text { if and only if } \hat{t}<t * \text {. }
$$

This "if and only if" result is much stronger. Recall that if the MNE has entered by $t *$, then both the branch plant and the autarky domestic firm would produce the same price/output combinations at each instant over $\left[t^{*}, \infty\right]$. (16) then equals zero by the definition of $t *$. But if $\hat{t}>t *$, then $p^{m}>p^{a}$ over the interval $[t *, \hat{t}]$ when the MNE continues to export, and thus (16) is strictly positive. Since $p$ is higher over the interval $[t * \hat{t}]$ while host-country income is identically equal to $\bar{Y}$ in either case, (16) positive is in fact sufficient for negative gains over $\left[t^{*}, \infty\right]$ relative to autarky. These losses may outweigh the usual gains from trade from importing over $\left[0, t^{*}\right]$ if this latter interval is short relative to $\left[t^{*}, \hat{t}\right]$. 
Of course, a monopoly MNE may well enter before $t *$ in our Cournot-Nash example. In addition, alternative assumptions can easily be found that guarantee early entry $\left(\hat{t}<t^{*}\right)$. Suppose that $(A)$ the (potential) host country firm makes an entry decision based on a Nash conjecture in prices; i.e., the entrant views current prices as parametric and (B) the MNE prices to prevent entry by this firm. Note that such a pricing policy is feasible for the MNE because of its lower costs. Under these assumptions, the MNE must choose a price $\mathrm{p}^{\mathrm{m}}$ such that the profits at $\mathrm{p}^{\mathrm{m}}$ are negative for the entrant at all possible levels of output. Since "all possible" includes $\mathrm{x}^{2}$, this implies that (13) holds or equivalently that $A$ is to the left of $N$ in Figure 2. The MNE equilibrium is superior to autarky.

A second situation in which gains are ensured occurs when there is competition among existing multinationals for exports to and for entry into the host country. If competition in exporting forces profits to zero, a MNE will enter at a time when the present value of its profits are zero. It then follows that the present value of profits for a potential host country firm are equal to $-F$ at $\hat{t}$. Viewed over $[\hat{t}, \infty]$, the host country gains the amount $F$ (the present value of profit repatriation is zero) plus consumer surplus gains over $\left[\hat{t}, t^{*}\right]$ relative to autarky ( $X$ is not available) or importing (the price of $\mathrm{X}$ would be higher). 


\section{Summary and Conclusions}

(1) The model developed in the paper adopts a theory of the firm approach to the MNE in which firms must incur a firm-specific (as well as a plant-specific) capital cost. This sunk cost becomes a "special firm asset" of the type often discussed in the empirical literature and leads to the existence of multi-plant economies of scale. These multi-plant economies give a two-plant firm (a MNE) a technical advantage over two independent single-plant firms and thus offer both the home and host countries potentially higher incomes through the resulting cost savings.

(2) This technology is embedded in a growing world in which one initially large country (the home country) already has a domestic producer at $T=0$ while a second smaller country (the host country) cannot initially support a domestic plant. The existing producer must choose when and if to build a branch plant (incur the plant-specific cost) in preference to exporting at a constant per-unit tariff/transportation cost. Two cases are distinguished. The first assumes that the host country never grows large enough to support two plants under the behavioral assumption that firms believe the post-entry game will be Nash in quantities. In this first case, the first firm to enter in the host country is assured of capturing or "appropriating" all monopoly rents. This "appropriability" is shown to imply that the home firm will always find it in its interests to build a branch plant (i.e., become a MNE) before it is profitable for a domestic entrant to do so. The home firm thus preempts entry with a branch plant after an initial phase of export sales.

(3) The second case assumes that the host country continues to grow to or past the point where two domestic plants can be supported. Given the assumption that the post-entry game is Nash in quantities, we show that the MNE 
cannot now prevent the eventual entry of a host country firm and thus cannot appropriate all future monopoly rents by early entry. This lack of appropriability means that the MNE may not build the first host-country plant and in fact may not enter at all (it continues to export to the host country). Results show that the MNE will always enter if firm-specific costs and tariff/ transportation costs are large relative to plant-specific costs, and will not enter if the cost difference is strongly in the opposite direction. As noted in the introduction, this gives us an empirically testable hypothesis that is consistent with the results of Caves (1982): MNE activity should be high in industries in which firm-specific and tariff/transportation costs are high relative to plant-specific costs.

(4) We also noted that the model can be reinterpreted to coincide with the ideas of Magee (1977) who coined the term "appropriability". Under this view, the firm-specific cost is interpreted as a barrier to entry faced by the host-country firm due to the lack of access to state-of-the-art technology. Instead of the host country growing, we then assume that the firm-specific cost disappears at some future time (e.g., the MNEs patent right expires). As in the growth case, the MNE will preempt entry with a branch plant to preserve its monopoly position.

(5) Since the welfare questions are more interesting for the host country, our welfare analysis concentrated on the choices facing that country. It was also limited to the simple case where the host country cannot support more than one plant. We noted that in the free-market equilibrium, the host country faces a trade-off between the technical efficiency of the branch plant (the host country never has to incur the cost of firm-specific capital) and the MNE market power (profits are repatriated that would otherwise have gone to host- 
country entrepreneurs). A sufficient condition for the host country to be better off in the free-market equilibrium relative to autarky is that the MNE build a branch plant at a date prior to which a domestic firm could not enter in autarky. Under the Cournot-Nash behavior assumed here, this condition is not necessarily satisfied. Two alternative assumptions do, however, ensure gains: (A) The MNE prices to prevent entry by Bertrand entrants in the host country or (B) there is competition among existing firms for entry into the host country. In the latter case, the gains to the host country exceed the savings in fixed costs $F$.

(6) As a final point, note that this model contains a certain irony with respect to current popular thinking on public policy. Suppose we equate the firm-specific capital cost with research and development investments on designing products or production processes. In our model, the host country gains from the MNE simply because the host country does not have to incur these costs. Yet public policy in Canada and other countries has been very concerned that the country losses due to the fact that foreign MNE do most of their $R$ and $D$ at home. Policies to increase domestic $R$ and $D$ rather than free ride on foreign $R$ and $D$ are under serious consideration or already in place. This is certainly not to say that there are no strategic reasons for being the $R$ and $D$ leader and the MNE home country (Spencer and Brander (1983)), but only to point out the relevant resource costs. 


\section{Eootnotes}

${ }^{1}$ Even a partial list of the many empirical studies would be rather lengthy, not to mention a description of their results. Caves (1982) provides an extensive and up-to-date bibliography, as well as an analysis and synthesis, of the various contributions.

2 An exception to this is Rao and Rutenberg (1979).

3 This assumption is a simple way of capturing the more general notion of the existence of a distinction between a plant and a firm (i.e. a group of plants under joint control). This notion is obviously crucial to any discussion of MNE activity.

${ }^{4}$ Allowing an arbitrary number of potential MNE's would not significantly alter the important results of Section 3 but would dramatically complicate the analysis.

${ }^{5}$ Some of the analysis of this section was suggested to us by Eaton and Lipsey's (1979) model of preemptive entry in a spatial market. Our model differs in four substantial ways from this specification. (1) Ours is a non-spatial model which (as noted by Eaton and Lipsey) does not imply that entry can always be preempted. (2) We have a firm-specific in addition to a plant-specific fixed cost which both fits the stylized facts about MNE and plays an important role in the analysis. (3) Our model has everywhere decreasing average cost so that the number of firms is not guaranteed to increase with the size of the economy. (4) We have an explicit model of the post-entry game which is only implicit in Eaton and Lipsey. As a consequence, somewhat different conclusions are reached.

${ }^{6}$ As will be seen, the assumption that $n>2$ simply guarantees that in the problem considered there is competition for entry by host-country producers so that, at the time of entry, the present value of a host-country firm's profits is zero.

7 This assumption on the output rule simply captures the fact that, at time $t$, firms make their output decisions after determining whether or not to build a plant..

${ }^{8}$ It is also assumed that demand is sufficiently we11-behaved that there exists a unique $t$ for which $R_{t}\left(X_{h}^{m}\right)-r G=R_{t}\left(X_{E}^{m}\right)-s X_{E}^{m}$, and it is assumed that this is the time at which the MNE would invest were it to be a monopolist in the host country for all $t$ (i.e. this $t$ defines a profit maximum).

${ }^{9}$ Given our assumptions, it will be the unique optimum, in fact.

${ }^{10}$ In particular, if entry preemption required that the MNE invest before $t_{1}$ it would still be in the MNE's interest to preempt entry. 
11

It is still important, of course, that $F>0$. If there were no special firm assets, then one would need to explain why the MNE operated a branch plant rather than simply licensing production to a host-country firm.

12 We assume that if the MNE operates more than one plant, it coordinates its output decisions across plants so as to maximize the sum of plant profits. Were the MNE to operate its branch plants as Nash competitors, this result would not go through. However, unless the MNE licenses production to independent hostcountry producers, we see no way that it can credibly commit to operating plants as Nash competitors. Further, in this model, the existence of the "special firm assets" rule out licensing as an alternative.

${ }^{13}$ Eaton and Lipsey (1979) do not get this duopoly result but rather suggest that the first entrant can maintain a monopoly position in the non-spatial case. But there is no explicit model of entry or post-entry behavior in their paper and thus it is unclear where this result comes from. It is likely correct for some type of behavior other than the Nash behavior assumed here.

${ }^{14}$ This limiting case obviously violates demand assumption (ii). Nonetheless, it provides a very sharp example of the notions embodied in Propositions 4 and 5 as well as a clear-cut case in which MNE investment does occur.

${ }^{15}$ It should be noted that this result holds for s strictly positive. For $s=0$ the result is trivial. Further, since $v_{t}$ is not continuous in $s$ (it has a discontinuity at $s=0$ ) the condition $R_{t}\left(X_{h}^{c}\right)<2 R_{t}\left(X_{2 h}^{c}\right)$ is necessary for the result to hold since limiting arguments are invalid at $s=0$. 


\section{REFERENCES}

Caves, Richard E., "Investment and Location Policies of Multinational Companies," Harvard University Working Paper (1980).

Caves, Richard E., Multinational Enterprise and Economic Analysis, Cambridge University Press (198.2) .

Caves, Richard E., Michael Porter and Michael Spence, Competition in the Open Economy: A Model Applied to Canada, Harvard University Press (1980). Dixit, Avinash, "International Trade Policy for Oligopolistic Industries," Princeton University Working Paper (1983).

Dixit, Avinash, and Victor Norman, Theory of International Trade, Cambridge University Press (1980).

Eaton, B. Curtis, and Richard Lipsey, "The Theory of Market Preemption; The Persistence of Excess Capacity and Monopoly in Growing Spatial Markets," Economica 46 (1979), pp. 149-158.

Helpman, Elhanan, "A Simple Theory of International Trade with Multinational Corporations," Journal of Political Economy (1984), forthcoming.

Helpman, Elhanan, "A Theory of Multinational Corporations and the Structure of Foreign Trade," Harvard Institute of Economic Research, Discussion Paper 961 (1983a).

Helpman, EIhanan, "A Theory of Multinational Corporations and the Structure of Foreign Trade - Part II: Vertical Integration," Harvard Institute for Economic Research, Discussion Paper 969 (1983b).

Magee, Stephen P., "Applications of the Dynamic Limit Pricing Model to the Price of Technology and International Technology Transfer," in K. Brunner and A. Meltzer (editors), Optimal Policies, Control Theory, and Technology Exports, North Holland (1977), pp. 203-224. 
Markusen, James R., "Trade and the Gains from Trade with Imperfect Competition," Journal of International Economics 11 (1981), pp. 531-551.

Markusen, James R., "Multinationals, Multi-Plant Economies, and the Gains from Trade," Journal of International Economics 14 (1984), forthcoming.

Markusen, James R., and James R. Melvin, "The Gains from Trade Theorem with Increasing Returns to Scale," in H. Kierzkowski (editor), Monopolistic Competition in International Trade, Oxford University Press (1984), Pp. 10-33.

Rao, R. and D. Rutenberg, "Preempting an Altert Rival: Strategic Timing of a First Plant by Analysis of Sophisticated Rivalry," Be11 Journal of Economics (1979), Pp. $412-428$.

Spencer, Barbara and James Brander, "International $R$ and $D$ Rivalry and Industrial Strategy," Review of Economic Studies (1983), 


\section{Appendix}

This Appendix contains the proofs for all of the propositions. in Section 3. In addition to the notation employed there, we let $H_{t}=0$ indicate that no host-country plants exist while $H_{t}=1$ indicates that at least one plant exists. We also let $I^{1}$ indicate the investment rule for the MNE; and $X^{N}$ the Nash equilibrium output for any arbitrary number of firms $N$.

\section{A. One Host-Country Plant}

This section provides results relating to the analysis in Section $3 \mathrm{~A}$. The first relates to the strategy of the $n$ entrants.

Lemma 1: If $H_{t_{1}}^{-}=0$ and $I_{t_{1}}^{1}\left(H_{t_{1}}^{-}\right)=0$ (i.e. the MNE does not invest at $t_{1}$ ), then the optimal strategy for the $n>2$ entrants is given by
(1) $I_{t_{1}}^{j}\left(H_{t_{1}}^{-}\right)=1$ for some $j$
(1a) $I_{t_{1}}^{k}\left(H_{t_{1}}^{-}\right)=0 \quad \forall k \neq j$
(2)

$$
I_{t}^{j}\left(H_{t}^{-}\right)=0 \quad t>t_{1}
$$
(2a) $I_{t}^{k}\left(H_{t}^{-}\right)=0 \quad \forall k \neq j, t>t_{1}, H_{t}^{-}=1$
(3a) $I_{t}^{l}\left(H_{t}^{-}\right)=1 \quad \& \neq k \neq j, t>t_{1}, H_{t}^{-}=0$
(4a) $I_{t}^{k}\left(H_{t}^{-}\right)=0 \quad k \neq l \neq j, t>t_{1}, H_{t}^{-}=0$

Proof : For firm j

Given ( $1 a$ ) and (3a) and demand assumption (iii) j can do no better by setting $I_{t}^{j}\left(H_{t}^{-}\right)=0$ for all $t \geq t_{1}$ (i.e. $V_{t_{1}}=0$ in either case). Further, given (3a) and (4a) and demand assumption (iv), (2) is the best firm $j$ can do whether $I_{t_{1}}^{j}\left(H_{t}^{-}\right)=0$ or $I_{t_{1}}^{j}\left(H_{t}^{-}\right)=1$.

For firms $k \neq i$

Given demand as sumption (iv) and (1), (1) and (2a) follow immediately. (3a) and (4a) follow from demand assumption (iii) and (2). That is, if any firm 
$k \neq l \neq j$ were to choose $I_{t}^{k}\left(H_{t}^{-}\right)=1$, then (iv) would imply $v_{t}^{k}<0$. For $l \neq k \neq j$, demand assumption (iii) and (2) imply that $v^{l}>0$ if $I_{t}^{l}\left(H_{t}^{-}=0\right)=1$ for $t>t_{1}$.

These results can be used to prove the following concerning the strategy of the MNE:

Lemma 2: There exists a half open interval $\left(t_{1}-\epsilon, t_{1}\right]$ such that investment by the $\mathbb{M N E}$ at any $t$ in this interval dominates a strategy of no investment (i.e. $\left.I_{t}^{1}\left(H_{t}^{-}\right)=0 \quad \forall t\right)$.

Proof: Lemma 1 above implies that, were the MNE not to invest, then at $t=t_{1}$ MNE profits would be given by

(A.1) $\quad v_{t_{1}}^{E}=\int_{t_{1}}^{\infty}\left[R_{T}\left(X_{E}^{c}\right)-s x_{E}^{c}\right] e^{-r\left(\tau-t_{1}\right)} d \tau$

where $X_{E}^{c}$ is the equilibrium level of MNE exports given a host-country producer. Were the MNE to invest at $t_{1}$, its profits would be

(A.2) $\quad v_{t_{1}}^{m}=\int_{t_{1}}^{\infty} R_{\tau}\left(x_{h}^{m}\right) e^{-r\left(\tau-t_{1}\right)} d \tau-G$.

Since as a monopolist, the MNE can coordinate host-country production and exports to maximize profits (which implies setting exports to zero), it must be that

(A.3) $\quad v_{t_{1}}^{m}>v_{t_{1}}^{c}=\int_{t_{1}}^{\infty}\left[R_{T}\left(X_{E}^{c}\right)-s X_{E}^{c}\right] e^{-r\left(T-t_{1}\right)} d \tau+\int_{t_{1}}^{\infty} R_{T}\left(X_{D}^{c}\right) e^{-r\left(T-t_{1}\right)} d \tau-G$.

From the definition of $t_{1}$, however,

(A. $\left.3^{\prime}\right) \quad v_{t_{1}}^{m}>v_{t_{1}}^{c}=\int_{t_{1}}^{\infty}\left[R_{\tau}\left(X_{E}^{c}\right)-s x_{E}^{c}\right) e^{-r\left(T-t_{1}\right)} d \tau+F>v_{t_{1}}^{E}$. 
Therefore, the profits to the $\mathrm{MNE}$ from investing at $t_{1}$ strictly dominate those from not investing. The remainder of the proof follows immediately from the fact that $V$ is continuous in $t$.

Given these two results, we can prove the following:

Theorem 1: Given demand assumptions (i)-(iv), the perfect Nash equilibrium of the game is given by:

For the MNE:

$$
\begin{aligned}
& I_{t}^{1}\left(H_{t}^{-}\right)=0 \quad \forall t<\hat{t} \leq t_{1} \\
& x_{t}^{1}\left(H_{t}^{+}\right)=x_{E}^{m} \forall t<\hat{t} \quad H_{t}^{+}=0 \\
& I_{t}^{1}\left(H_{t}^{-}\right)=1 \quad t=\hat{t}, H_{t}^{-}=0 \\
& x_{t}^{1}\left(H_{t}^{+}\right)=x_{H}^{m} \quad t \geq \hat{t} \quad H_{t}^{+}=1 \\
& I_{t}^{1}\left(H_{t}^{-}\right)=0 \quad t=\hat{t}, H_{t}^{-}=1 \\
& \text { and the MNE operates } \\
& I_{t}^{1}\left(H_{t}^{-}\right)=1 \quad \hat{t}<t \leq t_{1}, H_{t}^{-}=0 \\
& \text { the only host-country plant } \\
& I_{t}^{1}\left(H_{t}^{-}\right)=0 \quad t>\hat{t}=t_{1} \\
& \mathrm{x}_{t}^{1}\left(\mathrm{H}_{t}^{+}\right)=\mathrm{x}^{N} \forall \mathrm{t} \text { and any arbitrary } \mathrm{H}_{t}^{+} \text {. }
\end{aligned}
$$

\section{For the Entrants:}

$$
\begin{aligned}
& I_{t}^{j}\left(H_{t}^{-}\right)=0 \quad \forall t \leq t_{1} \\
& I_{t}^{k}\left(H_{t}^{-}\right)=0 \quad \forall t \leq t_{1}, k \neq j \\
& I_{t}^{j}\left(H_{t}^{-}\right)=0 \quad V t>t_{1}, H_{t}^{-}=1 \\
& I_{t}^{k}\left(H_{t}^{-}\right)=0 \quad \forall t>t_{1}, k \neq j, H_{t}^{-}=1 \\
& I_{t}^{j}\left(H_{t}^{-}\right)=1 \quad \forall t>t_{1}, H_{t}^{-}=0 \\
& I_{t}^{l}\left(H_{t}^{-}\right)=1 \quad \forall t>t_{1}, l \neq k \neq j, H_{t}^{-}=0 \\
& I_{t}^{k}\left(H_{t}^{-}\right)=0 \quad \forall t>t_{1}, k \neq l \neq j, H_{t}^{-}=0 \\
& \mathrm{x}_{\mathrm{t}}^{\mathrm{j}}\left(\mathrm{H}_{\mathrm{t}}^{+}\right)=0 \quad \forall \mathrm{t} \leq \mathrm{t}_{1} \\
& \mathrm{x}_{\mathrm{t}}^{\mathrm{k}}\left(\mathrm{H}_{\mathrm{t}}^{+}\right)=0 \quad \forall \mathrm{t} \leq \mathrm{t}_{1}, \mathrm{k} \neq \mathrm{j} \\
& x_{t}^{j}\left(H_{t}^{+}\right)=0 \quad \forall t>t_{1}, H_{t}^{+}=1 \\
& x_{t}^{k}\left(H_{t}^{+}\right)=0 \quad \forall t>t_{1}, k \neq l \neq j, H_{t}^{+}=1 \\
& \text { and } j \text { does not operate a } \\
& \text { branch plant } \\
& x_{t}^{l}\left(H_{t}^{+}\right)=0 \quad \forall t>t_{1}, l \neq k \neq j, H_{t}^{+}=1 \\
& x_{t}^{j}\left(H_{t}^{+}\right)=x^{N} \forall t>t_{1}, H_{t}^{+}=1 \\
& \text { and } j \text { does operate } a \\
& \text { branch plant } \\
& x_{t}^{\ell}\left(H_{t}^{+}\right)=x_{h}^{N} \forall t>t_{1}, \& \neq k \neq j, H_{t}^{+}=1 \\
& \text { and } \& \text { does operate a plant. }
\end{aligned}
$$


Proof: For the MNE, two cases can be defined

(i) $\hat{t}<t_{1}$ such that $\mathrm{R}_{\hat{t}}\left(X_{E}^{m}\right)-s X_{E}^{m}=R_{\hat{E}}\left(X_{h}^{m}\right)-r G$

Given the investment and output strategies of the entrants, were the MNE to invest at any $t^{\prime}<t_{1}$ it would operate as a monopoly in the host country for all $t$. The profits of the MNE at any time $t<t^{\prime}$ would then be (A.4) $v_{t}=\int_{t}^{t^{\prime}}\left[R_{\tau}\left(X_{E}^{m}\right)-s X_{E}^{m}\right] e^{-r(T-t)} d \tau+\int_{t}^{\infty} \cdot R_{T}\left(X_{h}^{m}\right) e^{-r(T-t)} d \tau-G e^{-r\left(t^{\prime}-t\right)}$ Given the MNE operates as a monopolist, the profit maximizing time of investment is that $t^{\prime}$ for which $\frac{d V}{d t}=0$; or the $t^{\prime}$ for which $R_{t} \cdot\left(X_{E}^{m}\right)-s X_{E}^{m}=R_{t} \cdot\left(X_{h}^{m}\right)-r G$. This, though, is just $\hat{t}$. Further, since $\hat{t}<t_{1}$, investment at $\hat{t}$ guarantees the MNE a monopoly position. and so is optimal. Given this and the strategies of the entrants, the optimality of the remainder of the MNE's investment and output strategies follows immediately.

(ii) $\forall t \leq t_{1}, R_{t}\left(X_{E}^{m}\right)-s x_{E}^{m}>R_{t}\left(X_{h}^{m}\right)-r G$

From Lemma 2, investment on the interval $\left(t_{1}-\varepsilon, t_{1}\right)$ dominates no investment. Further, since $R_{t}\left(X_{E}^{m}\right)-s X_{E}^{m}>R_{t}\left(X_{h}^{m}\right)-r G \forall t \leq t_{1}$ investment at $t_{1}$ dominates investment prior to $t_{1}$. Given the strategies of the entrants, investment at $t_{1}$ also dominates investment after $t_{1}$. Again the remainder of the proof follows immediately.

\section{For the Entrants}

Given the strategy of the MNE, the result for the entrant follows immediately from the proof of Lemma 1.

Remark: Obviously, Propositions 1 and 2 follow immediately from this theorem. 


\section{B. Two Host-Country Plants}

This section contains results which apply to the analysis of Section 3B. The first deals with the ability of the MNE to credibly proliferate branch plants. It is

Proposition 3: In equilibrium, the investment rule for the MNE must be such that, if there exists a $t=\hat{t}$ for which $I_{\hat{t}}^{1}=1, I_{t}^{1}=0$ for all $t \neq \hat{t}$.

Proof: Suppose there existed exactly one other $\underline{t}>\hat{t}$ such that, for the MNE, $I_{\underline{t}}^{1}=1$. Since $G$ is sunk, and marginal cost, $c$, is a constant, the two-plant joint-profit maximizing output for the MNE, given any output and investment strategies for the entrants, is identical to the one-plant output. If we define $v_{\underline{t}}^{l}$ as the profits of a one-plant MNE at $\underline{t}$ given its strategy and the strategies of the entrants, it must be, therefore, that the profits of a twoplant MNE is $v_{\underline{t}}^{2}=v_{\underline{t}}^{1}-G<v_{\underline{t}}^{1}$. Therefore investment at $\underline{t}$ cannot be an equilibrium strategy. The extension to multiple investment times is obvious.

Corollary: An obvious corollary to this result is that no entrant can credibly preempt entry through a proliferation of plants either.

Although we do not prove this here, it is easy to show by analysis similar to that of Lemma 1 that if the MNE does not invest at or before $t_{1}$, the equilibrium strategy for the entrants will imply that an independent hostcountry firm will enter at $t_{1}$. If the MNE does not invest at or before $t_{3}$, the equilibrium strategy for the entrants (and Proposition 3) implies that another independent host-country firm will enter at $t_{3^{*}}$. If the MNE does invest at or before $t_{1}$, an independent host-country firm will enter at $t_{2} \cdot$ Given this, we can prove the following: 
Proposition 4: If an investment strategy for the MNE imriies that $I_{t}=0$ for all $t \leq t_{1}$; and if there exists a $\bar{t}$ such that $t_{1}<\bar{t}<t_{3}$ and $R_{E}\left(X_{h}^{c}\right)-r G=R_{E}\left(X_{E}^{c}\right)-s X_{E}^{c}$, then $I_{\bar{t}}^{1}=1$ for the MNE.

Proof: If the MNE were to invest at some $t^{\prime \prime}$ such that $t_{1}<t^{\prime \prime}<t_{3}$ then, from the equilibrium strategy of the entrants, it would preempt all future entry. The MNE's profits at any $t$ such that $t_{1}<t<t^{\prime \prime}$ would then be given by (A.5) $v_{t}=\int_{t}^{t^{\prime \prime}}\left[R_{\tau}\left(X_{E}^{c}\right)-s X_{E}^{c}\right] e^{-r(\tau-t)} d \tau+\int_{t}^{\infty} R_{T}\left(X_{h}^{c}\right) e^{-r(\tau-t)} d \tau-G e^{-r\left(t^{\prime \prime}-t\right)}$ Given no future entry, the profit-maximizing investment time would be given by that $t=\bar{t}$ for which $R_{\bar{t}}\left(X_{h}^{c}\right)-r G=R_{\bar{t}}\left(X_{E}^{c}\right)-s X_{E}^{c}$. Since $\bar{t}<t_{3}$, it fulfills the definition of $t^{\prime \prime}$, so that entry is preempted and investment is optimal.

Given this result, we can prove the following:

Lemma 3: If there exists a $t=\bar{t}$ defined as in Proposition 4; and if, in additiol., $t_{1}<\bar{t}<t_{2}$, then there exists $a \hat{t} \leq t_{1}$ such that investment by the MNE at $\hat{t}$ dominates investment at $\vec{t}_{\text {。 }}$

Proof: Were the MNE not to invest at $t_{1}$, then from Proposition 4 and the strategy of the entrants, its profits would be

(A.6) $v_{t_{1}}^{E}=\int_{t_{1}}^{\bar{t}}\left[R_{T}\left(X_{E}^{c}\right)-s X_{E}^{c}\right] e^{-r\left(T-t_{1}\right)} d \tau+\int_{\bar{t}}^{\infty} R_{T}\left(X_{h}^{c}\right) e^{-r\left(T-t_{1}\right)} d \tau-G e^{-r\left(\bar{t}-t_{1}\right)}$

If the MNE were to invest at $t_{1}$, its profits would be

(A.7) $v_{t_{1}}^{m}=\int_{t_{1}}^{t_{2}} R_{\tau}\left(X_{h}^{m}\right) e^{-r\left(\tau-t_{1}\right)} d \tau+\int_{t_{2}}^{\infty} R_{\tau}\left(X_{h}^{c}\right) e^{-r\left(\tau-t_{1}\right)} d \tau-G$.

Since over the interval $\left[t_{1}, t_{2}\right)$ the MNE acts as a monopolist, it can coordinate host-country production and exports to maximize profits (which implies setting exports to zero). This implies that 
(A.8) $v_{t_{1}}^{m}>v_{t_{1}}^{c}=\int_{t_{1}}^{\bar{t}}\left[R_{T}\left(X_{E}^{c}\right)-s x_{E}^{c}\right] e^{-r\left(\tau-t_{1}\right)} d \tau+\int_{t_{1}}^{\bar{t}} R_{T}\left(X_{D}^{c}\right) e^{-r\left(\tau-t_{1}\right)} d \tau+$

$$
\int_{\bar{t}}^{\infty} R_{T}\left(X_{h}^{c}\right) e^{-r\left(\tau-t_{1}\right)} d \tau-G
$$

From the definition of $t_{1}$

(A.9) $v_{t_{1}}^{m}>v_{t_{1}}^{c}=\int_{t_{1}}^{\bar{t}}\left[R_{\tau}\left(X_{E}^{c}\right)-s X_{E}^{c}\right] e^{-r\left(\tau-t_{1}\right)} d \tau+F$.

From (A.5) $v_{t_{1}}^{m}>v_{t_{1}}^{c}>v_{t_{1}}^{E}$ if

(A.10) $F>\int_{\bar{t}}^{\infty} R_{T}\left(X_{h}^{c}\right) e^{-r\left(\tau-t_{1}\right)} d \tau-G e^{-r\left(\bar{t}-t_{1}\right)}$.

This, however, must be the case. For, from the definition of $t_{2}$ and the fact that $\bar{t}<t_{2}$, it must be that

(A.11) $\int_{\bar{t}}^{\infty} R_{T}\left(X_{h}^{c}\right) e^{-r(T-\bar{t})} d T-G<F$.

Multiplying the LHS of (A.11) by $e^{-r\left(\bar{t}-t_{1}\right)}<1$, one then obtains

(A.12) $\int_{\bar{t}}^{\infty} R_{T}\left(X_{h}^{c}\right) e^{-r\left(T-t_{1}\right)} d \tau-G e^{-r\left(\bar{t}-t_{1}\right)}<F$,

the desired result. Thus $v_{t_{1}}^{m}>v_{t_{1}}^{c}>v_{t_{1}}^{E}$, and the MNE prefers to invest at $t_{1}$ rather than $\bar{t}$. Continuity proves the result for some interval $\left(t_{1}-\varepsilon, t_{1}\right]$.

Corollary: Arguments similar to those employed in Theorem 1 can be used here to prove that investment by the MNE at some $\hat{t}<t_{1}$ is an equilibrium strategy. Proposition 5 therefore follows as a corollary of Lemma 3. 
Before proceeding with a proof of Proposition 6, we must introduce one additional concept. This is the notion of an s-economy. Clearly, the equilibrium levels of individual firm output and so the values of $t_{1}, t_{2}$ and $t_{3}$ depend on the value of the tariff/transportation cost, $s$. Therefore, a demand specification which would fulfill assumptions (i)-(ivc) for one value of $s$ may not for a higher (lower) value of $s$. We define an s-economy as an economy which fulfills demand assumptions (i)-(ivc) given the tariff transportation cost takes on a particular value s. Revenues net of variable costs in such an economy are given by the function $R_{t}^{s}(\cdot)$.

We also define the notion of the limit economy. This is the economy which fulfills demand assumptions (i)-(ivc) given $s=0$. Revenues net of variable costs in this economy are given by the function $R_{t}^{0}(\cdot)$. From the definition of $t_{1}, t_{2}$ and $t_{3}$, this economy has the property that $t_{1}=t_{2}<t_{3}<\infty$ (since the level of MNE exports is identical to the level of output were the MNE to operate a host-country plant). Finally, we say that a sequence of s-economies converges to the limit economy if, as $s$ approaches zero, the equilibrium outputs of each firm at each $t$ converge to those in the limit economy (i.e. the rule $X\left(H_{t}^{+} ; s\right)$, and so $R_{t}^{s}(\cdot)$ is continuous in $\left.s\right)$. We assume in what follows that this is the case. (If the demand specification in the limit economy were given by $X=f\left(p_{t}\right)$, then demand specifications in the $s$-economies of the form $X=f\left(p_{t}\right) / 1+s$ would satisfy this convergence property.)

Given our assumptions, we show first that, for sufficiently small s, if the MNE has not invested by $t_{3}$, it will not pay to do so.

Lemma 4: Given the assumptions of Proposition 6; and given that, for the MNE, $I_{t}^{1}=0 \mathrm{Vt}<t_{3}$, there exists a half-open interval $(0, \hat{\mathrm{s}}]$ such that, for all $\mathrm{s}$ in this inverval, the profit-maximizing strategy for the $\mathrm{MNE}$ implies $I_{t}=0 \mathrm{Vt} \geq \mathrm{t}_{3^{\circ}}$. 
Proof: Consider an arbitrary s-economy. Were the MNE to invest at $t_{3}$, its profits would be given by

$$
v_{t_{3}}^{c}=\int_{t_{3}}^{\infty} R_{T}^{s}\left(x_{h}^{c}\right) e^{-r\left(\tau-t_{3}\right)} d \tau-G
$$

Were the MNE not to invest at $t_{3}$, a second host-country firm would enter, resulting in MNE profits of

$$
\text { (A.14) } \quad v_{t_{3}}^{E}=\int_{t_{3}}^{\infty}\left[R_{\tau}^{s}\left(x_{E}^{2 c}\right)-s x_{E}^{2 c}\right] e^{-r\left(\tau-t_{3}\right)} d \tau \text {, }
$$

where $\mathrm{X}_{\mathrm{E}}^{2 \mathrm{c}}$ is the equilibrium level of MNE exports given the MNE competes with two host-country firms. Investment at $t_{3}$ is dominated by no investment if

$$
v_{t_{3}}^{E}-v_{t_{3}}^{c}=\int_{t_{3}}^{\infty}\left[R_{T}^{s}\left(X_{E}^{2 c}\right)-s X_{E}^{2 c}-R_{T}^{s}\left(X_{h}^{c}\right)\right] e^{-r\left(\tau-t_{3}\right)} d \tau+G>0
$$

From the definition of $t_{3}, G=\int_{t_{3}}^{\infty} R_{T}^{s}\left(x_{2 D}^{c}\right) e^{-r\left(\tau-t_{3}\right)} d \tau$; and, therefore, no investment dominates investment if

$$
\text { (A.15 }) \quad v_{t_{3}}^{E}-v_{t_{3}}^{c}=\int_{t_{3}}^{. \infty}\left[R_{T}^{s}\left(X_{E}^{2 c}\right)-s x_{E}^{2 c}+R_{T}^{s}\left(X_{2 D}^{c}\right)-R_{T}^{s}\left(X_{h}^{c}\right)\right] e^{-r\left(T-t_{3}\right)}>0
$$

If we take a sequence of s-economies converging to the limit economy then, by definition $x_{E}^{2 c} \rightarrow x_{2 H}^{c}$ and $x_{2 D}^{c} \rightarrow x_{2 H}^{c}$ as $s \rightarrow 0$. Further, no investment dominates investment on the interval $(0, \hat{s}]$ if

$$
\lim _{s \rightarrow 0} v_{t_{3}}^{E}-V_{t_{3}}^{c}=\int_{t_{3}}^{\infty}\left[R_{\tau}^{o}\left(x_{2 h}^{c}\right)+R_{T}^{o}\left(x_{2 h}^{c}\right)-R_{T}^{o}\left(x_{h}^{c}\right)\right] e^{-r\left(\tau-t_{3}\right)} d \tau>0
$$

By assumption, however, $2 R_{t}\left(X_{2 h}^{c}\right)>R_{t}\left(X_{h}^{c}\right) \forall t$ so that (A.16) holds and no investment is the profit-maximizing strategy for the MNE. 
Lemma 4 guarantees that if the MNE has not invested by $t_{3}$, then it will never invest. Clearly, however, if $s$ is sufficiently small relative to $G$ such that $R_{t_{3}}^{s}\left(X_{E}^{c}\right)-s X_{E}^{c}>R_{t_{3}}^{s}\left(X_{h}^{c}\right)-r G$, then if the MNE would not invest at $t_{3}$, it would not invest at any $t$ on the interval $\left(t_{1}, t_{3}\right)$. We define $s^{\prime}$ as the largest $s$ for which $R_{t_{3}}^{s}\left(X_{E}^{c}\right)-s X_{E}^{c} \geq R_{t_{3}}^{s}\left(X_{h}^{c}\right)-r G$. Then, if one defines $\vec{s}=\min \left\{\hat{s}, s^{\prime}\right\}$ it must be that for all $s$ on the half-open interval $(0, \bar{s}]$, if the MNE has not invested by $t_{1}$, it will not invest. Given this, we can now prove

Proposition 6: If, for $F=0, G>0, R_{t}\left(X_{h}^{c}\right)<2 R_{t}\left(x_{2 h}^{c}\right)$ for all $t$, then there exists an $\epsilon>0$ such that, for all $0<s \leq \epsilon$, the equilibrium strategy for the MNE implies that $I_{t}=0$ for a11 $t$.

Proof: Define $\epsilon$ such that $0<\epsilon \leq \bar{s}$. Then from the definition of $\bar{s}$, if the MNE has not invested by $t_{1}$, it will not invest. Its profits at $t_{1}$ in this case would be given by

(A.17) $v_{t_{1}}^{E}=\int_{t_{1}}^{t_{3}}\left[R_{T}^{s}\left(X_{E}^{c}\right)-s X_{E}^{c}\right] e^{-r\left(\tau-t_{1}\right)} d \tau+\int_{t_{3}}^{\infty}\left[R_{T}^{s}\left(x_{E}^{2 c}\right)-s X_{E}^{2 c}\right] e^{-r\left(T-t_{3}\right)} d \tau$. Were the MNE to invest at $t_{1}$ (given it has not already done so), its profits would be

(A.18) $v_{t_{1}}^{m}=\int_{t_{1}}^{t_{2}} R_{\tau}^{s}\left(x_{h}^{m}\right) e^{-r\left(\tau-t_{1}\right)} d \tau+\int_{t_{2}}^{t_{3}} R_{\tau}^{s}\left(x_{h}^{c}\right) e^{-r\left(\tau-t_{1}\right)} d \tau+\int_{t_{3}}^{\infty} R_{\tau}^{s}\left(x_{h}^{c}\right) e^{-r\left(T-t_{1}\right)} d \tau-G$ Again, no investment dominates investment at $t_{1}$ if $v_{t_{1}}^{E}-v_{t_{1}}^{m}>0$. If we take a sequence of s-economies converging to the limit economy, by definition, $x_{E}^{c} \rightarrow x_{h}^{c}$, $x_{E}^{2 c} \rightarrow x_{2 h}^{c}, x_{D}^{c} \rightarrow x_{h}^{c}$ as $s \rightarrow 0$. Given this, and the fact that, from the definition of $t_{1}, G=\int_{t_{1}}^{t_{3}} R_{T}^{s}\left(X_{D}^{c}\right) e^{-r\left(T-t_{1}\right)} d \tau+\int_{t_{3}}^{\infty} R_{T}^{s}\left(X_{2 D}^{c}\right) e^{-r\left(T-t_{1}\right)} d \tau$, no investment will dominate investment at $t_{1}$ on the interval $\left(0, s^{*} \leq \bar{s}\right]$ if 
(A.19) $\lim _{s \rightarrow 0} v_{t_{1}}^{E}-V_{t_{1}}^{m}=\int_{t_{3}}^{\infty}\left[2 R_{T}^{o}\left(x_{2 h}^{c}\right)-R_{T}^{o}\left(x_{h}^{c}\right)\right] e^{-r\left(\tau-t_{2}\right)} d \tau+\int_{t_{2}}^{t_{3}} R_{T}^{o}\left(x_{h}^{c}\right) e^{-r\left(\tau-t_{2}\right)} d \tau>0$ By assumption, however, $2 R_{T}\left(X_{2 h}^{c}\right)>R_{t}\left(X_{h}^{c}\right) \forall t$ and so no investment at $t_{1}$ dominates investment prior to $t_{1}$ as well. To complete the proof, we simply define a tariff/transportation cost $\epsilon<s^{*}$ and the s-economy associated with it. Then no investment in this economy is obviously an equilibrium strategy for the MNE.

Remark: While it is trivially true that the equilibrium strategy for the MNE involves no investment if $s=0$, the above result does not follow as a contimuous extension. If $s=0$, then investment by the MNE will not credibly deter any entry. By the definition of the s-economy, for any $s>0$, investment by the MNE will deter entry by a second host-country firm. Therefore, if the MNE invests, the maximized value of profits in the sequence of s-economies as $s$ is made small does not converge to the maximized value of profits in the $s=0$ economy. This is the reason for the additional as sumption that $2 R_{t}\left(x_{2 h}^{c}\right)>R_{t}\left(x_{h}^{c}\right)$. 


\begin{abstract}
$8101 C$
Markusen, James R. Factor Movements and Commodity Trade as Compliments: A Gurvey of some Cases.

Conlon, R.M. Comparison of Australian and Canadian Manufacturing Industries: Some Empirical Evidence.

$8103 C$

Conlon, R.M. The Incidence of Transport Cost and Tariff Protection: Some Australian Evidence.

$8104 C$

$8105 C$

$8106 C$

$8107 \mathrm{C}$

$8108 C$ D SU

8109 C D SU

$8110 \mathrm{C}$

$8111 \mathrm{C}$

Laidler, David. On the Case for Gradualism.

Wirick, Ronald G. Rational Expectations and Rational

stabilization Policy in an Open Economy

Mansur, Ahsan and John Whalley Numerical secification of Applied

General Equilibrium Models: Estimation, Calibration, and Data.

Burgess, David F., Energy Prices, Capital Formation, and Potential GNP

Jimenez, E. and Douglas H Keare. Kousing Consumption and Income in the Low Income Urban setting: Estimates from Panel Data in El silvador

Whalley, John Labour Migration and the North-South Debate

Manning, Richard and John McMillan Government Expenditure and Comparative Advantage

Freid, Joel and Peter bowitt Why Inflation Reduces Real Interest Rates
\end{abstract}

$8201 C$

$8202 C$

$8203 C$

$8204 C$

$8205 C$

$8206 C$

$8207 \mathrm{C}$

$8208 \mathrm{C}$

8209C DSU

\begin{abstract}
$\underline{1982}$
Manning, Richard and James R. Markusen Dynamic Non- Mbstitution and Long Run Production Possibilities
\end{abstract}

Feenstra, Robert and Ken Judd Tariffs, Technology Transfer, and Welfare

Ronald $W$. Jones, and Douglas D. Purvis: International Differences in Response to Common External shocks: The Role of Purchasing Power Parity

James A Brander and Barbara J. Spencer: Industrial strategy with Committed Firms

Whalley, John, The North-South Debate and the Terms of Trade: An Applied General Equilibrium Approach

Roger Betancourt, Christopher Clague, Arvind Panagariya CAPI TAL UTI II ZATI ON IN GENERAL EQUIII BRI UM

Mansur, Ahsan $H_{6}$ On the Estimation of Import and Export Demand Elasticities and Elasticity Pessimism.

Whalley, J, and Randy Wigle PRICE AND QUANTITY RIGIDITIES IN ADJUSTMENT TO TRADE POLICY CHANGES: ALTERNATIVE FORMULATIONS AND INITIAL CALCULATIONS

Jimenez, E. SQUATTING AND COMMUNITY ORGANIZATION IN DEVELOPING COUNTRIES: A CONCEPTUAL FRAMEWORK 
8210C Grossman, G.M. INTERNATIONAL COMPETITION AND THE UNIONIZED SECTOR

8211C Laldler,D. FRIEDMAN AND SCHWARTZ ON MONETARY TRENDS - A REVIEW ARTICLE

8212C Imam, M.H. and thalley, J. INCIDENCE ANALYSIS OF A SECTOR SPECIFIC MINIMUM WAGE IN A TWO SECTOR HARRIS-TODARO MODEL. 8213C Markusen, J.R. and Melvin, J.R. THE GAINS FROM TRADE THEOREM WITH INCREASING
RETURNS TO SCALE. 8214C INDUSTRIAL ORGANIZATION AND THE GENERAL EQUILIBRIUM COSTS OF PROTECTION IN
SMALL OPEN ECONOMIES.

8215C Laidler, D. DID MACROECONOMICS NEED THE RATIONAL EXPECTATIONS REVOLUTION?

8216C Whalley, J. and Wigle, R. ARE DEVELOPED COUNTRY MULTILATERAL TARIFF REDUCTIONS NECESSARILY BENEFICIAL FOR THE U.S.?

8217C Bade, R. and Parkin, M. IS STERLING M3 THE RIGHT AGGREGATE?

8218C Kosch, B. FIXED PRICE EQUIIIBRIA IN OPEN ECONOMIES.

$\underline{1983}$

8301C Kimbe11, L.J. and Harrison, G.W. ON THE SOLUTION OF GENERAL EQUILIBRIUM
MODELS.

8302C Melvin, J.R. A GENERAL EQUILIBRIUM ANALYSIS OF .CANADIAN OIL POLICY.

8303C Markusen, J.R. and Svensson, L.E.0. TRADE IN GOODS AND FACTORS WITH INTERNATIONAL DIFFERENCES IN TECHNOLOGY.

8304C Mohammad, S. Whalley, J. RENT SEEKING IN INDIA: ITS COSTS AND POLICY
SIGNIFICANCE.

8305C DSU Jimenez, E. TENURE SECURITY AND URBAN SỌUATTING.

8306C Parkin, M. WHAT CAN MACROECONOMIC THEORY TELL US ABOUT THE WAY DEFICITS
SHOULD BE MEASURED.

8307C Parkin, M. THE INFLATION DEBATE: AN ATTEMPT TO CLEAR THE AIR.

8308C Wooton, I. LABOUR MIGRATION IN A MODEL OF NORTH-SOUTH TRADE.

8309C Deardorff, A.V. THE DIRECTIONS OF DEVELOPING COUNTRIES TRADE: EXAMPLES
FROM PURE THEORY.

$8310 \mathrm{C}$ Manning, R. ADVANTAGEOUS REALLOCATIONS AND MULTIPLE EQUILIBRIA: RESULTS FOR THE THREE-AGENT TRANSFER PROBLEM. 
8311C DSU Mohammad, S. and Whalley, J. CONTROLS AND THE INTERSECTORAL TERMS OF
TRADE IN INDIA.

8312C Brecher, Richard A. and Choudhr1, Ehsan U. NEW PRODUCTS AND THE FACTOR
CONTENT OF INTERNATIONAL TRADE.

8313C Jones, R.W., Neary, J.P. and Ruane, F.P. TWO-WAY CAPITAL FLOWS: CROSS-
HAULING IN A MODEL OP FOREIGN INVESTMENT.

$8314 C$ DSU Follain, J.R. Jr. and Jimenez, E. THE DEMAND FOR HOUSING CHARACTERISTICS
IN DEVEIOPING COUNTRIES.

8315C Shoven, J.B. and Whalley, J. APPLIED GENERAL EQUILIBRIUM MEDELS OF
TAXATION AND INTERNATIONAL TRADE.

$8316 \mathrm{C}$ Boothe, Paul and Longworth David. SOME IRREGULAR REGULARITIES IN THE
CANADIAN/U.S. EXCHANGE MARKET.

8317C Hamilton, Bob and Whalley, John. BORDER TAX ADJUSTMENTS AND U.S. TRADE.

$8318 \mathrm{C}$ Neary, J. Peter, and Schwelnberger, Albert G. FACTOR CONTENT FUNCTIONS AND
THE THEORY OF INTERNATIONAL TRADE.

8319C Veall, Michael R. THE EXPENDITURE TAX AND PROGRESSIVITY.

8320C Melvin, James R. DOMESTIC EXCHANGE, TRANSPORTATION costs AND INTERNATIONAL
TRADE.

8321C Hamilton, Bob and Whalley, John. GEOGRAPHICALLY DISCRIMINATORY TRADE
ARRANGEMENTS. 8322C Bale, Harvey Jr. INVESTMENT FRICTIONS AND OPPORTUNITIES IN BTLATERAL
U.S.-CANADIAN TRADE RELATIONS.

$8323 \mathrm{C}$ Wonnacott, R.J. CANADA-U.S. ECONOMIC RELATIONS-A CANADIAN VIEW.

8324C Stern, Robert M. U.S.-CANADIAN TRADE AND INVESTMENT FRICTIONS: THE
U.S.: VIEW.

8325C Harrison, Glenn, H. and Kimbe11, Larry, J. HOW ROBUST IS NUMERICAL GENERAL EQUILIBRIUM ANALYSIS?

8326C Wonnacott, R.J. THE TASK FORCE PROPOSAL ON AUTO CONTENT: WOULD THIS SIMPLY EXTEND THE AUTO PACT, OR PUT IT AT SERIOUS RISK?

8327C Bradford, James C. CANADIAN DEFENCE TRADE WITH THE U.S. Conklin, David. SUBSIDY PACTS.

Rugman, Alan M. THE BEHAVIOUR OF U.S. SUBSIDARIES IN CANADA:

IMPLICATIONS FOR TRADE AND INVESTMENTS. 
8328C Boyer, Kenneth D. U.S.-CANADIAN TRANSPORTATION ISSUES.

8329C Bird, Richard $M$. and Brean, Donald J.S. CANADA-U.S. TAX RELATIONS: ISSUES AND PERSPECTIVES.

8330C Moroz, Andrew R. CANADA-UNITED STATES AUTOMOTIVE TRADE AND TRADE POLICY ISSUES.

8331C Grey, Rodney de C. and Curtis, John. INSTITUTIONAL ARRANGEMENTS FOR U.S.-CANADIAN NEGOTIATIONS. PART I: CANADA-U.S. TRADE AND ECONOMIC ISSUES: DO WE NEED A NEW INSTITUTION? PART II: INSTITUTIONAL ARRANGEMENTS FOR MANAGING THE CANADA-U.S. ECONOMIC RELATIONSHIP.

\section{4}

8401C Harrison, Glenn $W$. and Manning, Richard. BEST APPROXIMATE AGGREGATION OF INPUT-OUTPUT SYSTEMS.

8402C Parkin, Michael. CORE INFLATION: A REVIEW ESSAY.

8403C Blomqvist, Ảke, and McMahon, Gary. SIMULATING COMMERICAL POLICY IN A SMALL, OPEN DUAL ECONOMY WITH URBAN UNEMPLOYMENT: A GENERAL EQUILIBRIUM APPROACH.

8404C Wonnacott, Ronald. THE THEORY OF TRADE DISCRIMINATION: THE MIRROR IMAGE OF VINERIAN PREFERENCE THEORY?

8405C Whalley, John. IMPACTS OF A 50\% TARIFF REDUCTION IN AN EIGHT-REGION GLOBAL TRADE MODEL.

8406C Harrison, Glenn W. A GENERAL EQUILIBRIUM ANALYSIS OF TARIFT REDUCTIONS.

8407C Horstmann, Ignatius and Markusen, James R. STRATEGIC INVESTMENTS AND THE DEVELOPMENT OF MULTINATIONALS. 